\title{
TODDLER WITH RECURRENT ABDOMINAL PAIN: MIGRAINE?
}

Amit Saxena ${ }^{1}$, Vaishali More $^{2}$

HOW TO CITE THIS ARTICLE:

Amit Saxena, Vaishali More. "Toddler with Recurrent Abdominal Pain: Migraine?". Journal of Evolution of Medical and Dental Sciences 2014; Vol. 3, Issue 49, October 02; Page: 11771-11773,

DOI: $10.14260 /$ jemds $/ 2014 / 3547$

ABSTRACT: Abdominal migraine is a migraine variant, causing chronic idiopathic recurrent abdominal pain in 4-15\% of children. It is usually seen between the ages of seven to twelve years and is more common in girls, with peak prevalence at the age of ten years. We report a 3 year old girl suffering from recurrent abdominal pain since $1 \frac{1}{2}$ years of age, who underwent extensive investigations as well as diagnostic laparotomy with appendectomy, and was ultimately diagnosed to have abdominal migraine. She responded well to the prophylactic drug Flunarizine.

KEYWORDS: Recurrent abdominal pain, abdominal migraine, young age.

CASE REPORT: A three year old girl was referred with the complaint of episodes of severe abdominal pain since one and half years. It was dull aching, predominantly per umbilical, usually in the evening, intermittent, lasting for 1 to 2 hours, getting relieved on its own. Initially, there were 1 to 2 episodes per week and then the frequency increased to 2 episodes every alternate day. During the attack the child had anorexia, nausea, irritability and insomnia.

There was no history of vomiting, loose stools or fever. She was completely symptom free between two episodes. There was no history of Koch's or Koch's contact and she had gained adequate weight with no developmental delay. There was no history of migraine in either parent. The patient was being investigated since one and half year.

Complete blood count, liver function test, renal function test, urine, stool routine, X-ray abdomen, USG Abdomen, CT abdomen and barium meal study were all within normal limits. She did not respond to antacids and analgesics during the acute episodes and had received anthelminthic and antibiotics on multiple occasions.

She had also undergone diagnostic laparoscopy with appendectomy four months prior to presenting to us with persisting complaints even after the surgery. On examination, the patient was conscious, alert, active and cooperative. Her vital parameters and anthropometry were within normal limits. There was no pallor, icterus, cyanosis, clubbing, lead lines, lymphadenopathy or edema. Systemic examination did not reveal any abnormality apart from the operative scar mark on the abdomen.

A differential diagnosis of lead poisoning, acute intermittent porphyria and abdominal migraine were considered and the patient was investigated for the same. Blood lead level was $5 \mathrm{mcg} / \mathrm{dl}$. Urine porphobilinogen was negative. EEG was suggestive of epileptiform activity with spike pattern over right hemisphere and the diagnosis of abdominal migraine was made.

During the ward stay she had a severe attack of abdominal pain and she was loaded with injection valproic acid at $20 \mathrm{mg} / \mathrm{kg}$. In view of no response in 24 hours, she was started on oral flunarazine to which she responded. She was advised to continue tablet Flunarizine $2.5 \mathrm{mg}$ twice daily and valproic acid was omitted. She is asymptomatic for the past one year. 


\section{CASE REPORT}

DISCUSSION: Abdominal migraine (AM) is a subtype of recurrent abdominal pain, most commonly seen in children ${ }^{1}$.It affects $1-4 \%$ of children ${ }^{2}$ and is the causative factor in about $4-15 \%$ of children with chronic idiopathic recurrent abdominal pain. ${ }^{3}$ Presenting symptoms include acute, incapacitating, non-colicky per umbilical abdominal pain that lasts for one or more hours. Pallor, anorexia, nausea, vomiting, photophobia, or headache may be associated with the episodes, and a family history of migraine headaches is often noted.2

AM is a migraine variant which is usually seen between the ages of seven to twelve years and is more common in girls, with peak prevalence at the age of ten years. As against this, our patient though a girl child is probably the youngest case presenting at eighteen months of age. The diagnosis is mainly clinical after the exclusion of other causes of recurrent abdominal pain. Our patient fulfills the Rome III criteria for functional gastrointestinal disorders which are widely used to diagnose AM. ${ }^{4}$

EEG changes have also been reported in AM and were present in our case.5,6 $\mathrm{Abu}$ Arafeh et al compared the prevalence and clinical features of AM with migrainous headache and suggested that they have a common pathogenesis as the social, demographic, triggers and relieving factors were similar. ${ }^{1}$ Intravenous valproic acid was found to be effective in aborting abdominal migraine by Tan et $\mathrm{al}^{7}$, however, our patient did not respond to it.

A 51\% reduction in duration of acute attack of AM and $61 \%$ reduction in frequency were demonstrated with flunarizine by Kothare et al. ${ }^{8}$ Our patient responded to flunarizine and she has been asymptomatic for the past one year. Other drugs like pizotifen, propranolol and cyproheptadine have also been found to be effective for prophylactic use in AM1. Recent studies do suggest that infantile colic can be a manifestation of childhood migraine and later may manifest as migraine with or without aura. ${ }^{9}$

In fact some studies have proved that infant colic is an early life expression of migraine, especially if associated with maternal history of migraine. ${ }^{10,11}$ Hence, before surgical interventions, patients with recurrent abdominal pain should be assessed for migraine variants especially if there are no clinical signs of an acute abdomen.

\section{REFERENCES:}

1. Russell G, Abu-Arefeh I, Symon DN: Abdominal migraine: evidence for existence and treatment options. Pediatric Drugs 2002; 4: 1-8.

2. Popovich DM, Schentrup DM, Mc Alhany AL. Recognizing and diagnosing abdominal migraines. J Pediatr Health Care. 2010 Nov-Dec; 24: 372-7.

3. Bigal ME, Arruda MA: Migraine in the pediatric population - evolving concepts. Headche. 2010 Jul; 50: 1130-43.

4. Mostafa R. Rome III: The functional gastrointestinal disorders, third edition, 2006. World J Gastroenterol. 2008 April 7; 14: 2124-2125.

5. Sangermani R, Pirovano S, Vaccari R et al. Abdominal migraine simulating acute abdomen. Pediatr Med Chir. 1992 Mar - Apr; 14: 163-5.

6. Tan HJ, Suganthi C, Dhachayani S et al. The electroencephalogram changes in migrainuers. Med J Malaysia.2007 Mar; 62:56-8.

7. Tan V, Sahami AR, Peebles R et al. Abdominal migraine and treatment with intravenous valproic acid. Psychosomatics. 2006 Jul-Aug;47: 353-5. 
8. Kothare SV Efficacy of flunarizine in the prophylaxis of cyclical vomiting syndrome and abdominal migraine. Eur J Paediatr Neurol 2005; 9: 23-6.

9. Romanello S, Spiri D, Marcuzzi E et al. Association between childhood migraine and history of infantile colic. JAMA, 2013 Apr 17; 309 (15): 1607-12.

10. Gelfand AA, Thomas KC, Goadsby PJ. Before the headache: infantile colic as an early life expression of migraine. Neurology. 2012 Sep 25; 79 (13): 1392-6.

11. Gelfand AA Migraine and childhood periodic syndromes in children and adolescents. Curr Opin Neurol, 2013 Jun; 26 (3): 262-8.

\section{AUTHORS:}

1. Amit Saxena

2. Vaishali More

\section{PARTICULARS OF CONTRIBUTORS:}

1. Assistant Professor, Department of Paediatrics, D. Y. Patil Medical College, Nerul, Navi Mumbai.

2. Associate Professor, Department of Paediatrics, D. Y. Patil Medical College, Nerul, Navi Mumbai.

\section{NAME ADDRESS EMAIL ID OF THE CORRESPONDING AUTHOR:}

Dr. Amit Saxena,

Flat No. 102, Gurumahima Heights,

Sector 14, Sanpada,

Navi Mumbai-400705,

Maharashtra, India.

Email: dramitsaxena1981@gmail.com

Date of Submission: 15/09/2014.

Date of Peer Review: 16/09/2014.

Date of Acceptance: 25/09/2014.

Date of Publishing: 01/10/2014. 